\title{
Three years clinical outcome of hybrid fixed-fixed bridges
}

\author{
Mohammed M. AL- Moaleem ${ }^{1}$, Mahmoud M. Ammar' ${ }^{2}$ Mohsen A. Alhamzi ${ }^{3}$, \\ Mansoor Shariff ${ }^{4}$, Abdulla A. Dhabali ${ }^{5}$ \\ Assistant Professor of Fixed Prosthodontics, College of Dentistry, Jazan University, Saudi Arabia, Jazan \\ Assistant Professor of Removable Prosthodontics, College of Dentistry, Jazan University, KSA and Lecturer of \\ Removable Prosthodontics, Faculty of Dental Medicine, Al-Azhar University, Assuit Branch, Egypt. \\ Assistant Professor of Fixed Prosthodontics, College of Dentistry, Thamar University, Yemen. \\ Assistant Professor of Prosthodontics, Prosthodontics Department, College of Dentistry, King Khalid \\ University, Saudi Arabia, Abha. \\ Assistant Professor of Clinical Pharmacology \& Pharmacy Practice, Faculty of Pharmacy, Sana'a University, \\ Yemen
}

\begin{abstract}
Subject: Hybrid fixed-fixed partial dentures present a conservative approach to the conventional type when a single tooth is replaced in the posterior region with certain indications.

Aim: To evaluate various criteria's like, post-operative sensitivity, gingival response, de-bonding of the retainer, secondary caries, retainer fracture resistance and patient satisfaction.

Materials and methods: A total of 16 bridges were included in this clinical study. The patient selection, preparation techniques as well as bridges constructions were followed the current principles that recommended by the manufactures instructions and recent textbooks. Patients were clinically evaluated after 3 months from the final cementation. At 9, 18, and 36 months as follow-up period the patients were called by phone.

Results: A good rate success was observed during the different evaluation periods. Gingival inflammation of one case was reported during 18 month evaluation, while two cases with de-bonding and post-operative sensitivity were recorded during the 36 month. 100\% of patients were satisfied with these types of restorations.

Conclusions: Hybrid fixed-fixed retained bridges appear to be an effective restoration in a single posterior missing tooth. Practitioners should consider its use as an alternative to bilateral full crown retained restorations.
\end{abstract}

Key Words: Hybrid fixed prosthesis, Conventional bridges, Survival rate, Posterior teeth

\section{Introduction}

Several restorative options have been proposed for replacing missing posterior teeth: implants, porcelain fused to metal fixed partial dentures (FPD), removable partial denture and resin bonded FPDs. The economic factors, occlusal disturbances, lack of adequate bone support or excessive removal of healthy dental structures are some of the limiting factors in the indication of some restorative alternatives. ${ }^{[1,2]}$ However, some patients reject implant option because of higher cost or fear of surgery. Systemic problems may also contraindicate surgery. ${ }^{[3]}$ Porcelain fused to metal (PFM) full-coverage restorations is still viewed as standard restoration for missing posterior teeth; however, the preparation of two teeth is required for replacing a single tooth deficiency causing unnecessary dental tissue loss. ${ }^{[4]}$

The hybrid fixed-fixed prosthesis consists of an inlay bonded retainer with vital tooth in one of the abutments and a conventional retainer with vital or non-vital tooth on the other. These restorations are made of porcelain fused to metal. ${ }^{[5 \& 6]}$

Inlay retained FPD are indicated if the abutment teeth is having an existing amalgam restoration or caries ${ }^{[7]}$ or when there is drifting of abutment teeth with minimal or no occlusal forces from opposing arch. ${ }^{[8]}$ They are good alternative to conventional types, as they are less expensive, allow greater preservation of tooth structure and are easier for periodontal assessment. ${ }^{[9]}$ Posterior endodontically treated teeth (ETT) are subjected to greater loading than anterior teeth, also required cuspal coverage to prevent biting force from causing fractures. ${ }^{[5]}$ Fiber reinforced composite posts (FRC) had adequate mechanical properties as recent studies suggested that FRC posts contributed to the reinforcement and strengthening of ETT under full coverage crown restorations. ${ }^{[10]}$

The aim of this longitudinal clinical study therefore was to evaluate the clinical performance and survival rates of hybrid fixed-fixed bridges in subjects that were clinically indicated for prosthesis. After a follow up period ranging from 3 to 36 months, clinical success and/or failures was determined based on postoperative sensitivity, gingival response, de-bonding of the retainers, secondary caries, retainer fracture resistance and patient satisfaction. 


\section{Materials and methods}

Sixteen male patients, who were referred to Department of Prosthodontics from Department of oral diagnosis were selected based on the absolute clinical indications for the type of prosthesis. Their age ranged from 20 to 40 years and patients who were highly self-motivated, had good oral hygiene with no evidence of systemic disease and had an existing stable occlusion with no history or evidence of bruxism were included. The teeth that were replaced by the hybrid prosthesis were second premolars/ first molar only. Six cases for maxillary and ten cases of mandibular partially edentulous arches were respectively treated overall. Treatment plan for all patients included generalized motivation, oral hygiene maintenance program, preliminary mouth preparation that included removal and restoration of existing carious lesion, elimination of periodontal pockets and minor orthodontic treatment. Radiographic investigations (Figure-1) were followed by diagnostic cast mounting on programmed semi adjustable articulator.

\section{Case selection for inlay and teeth preparation:}

Inclusion criteria for inlay preparations were vital abutments with no evidence of mobility, presence of occlusal caries along with extensions or previous fillings (Figure-1a),occluso-gingival axial dimension at least 5 $\mathrm{mm}$, mesiodistaledentulous area up to $12 \mathrm{~mm}$ (Figure-1b,c),patients presenting with impacted third molars (Figur-1c), abnormal but stable occlusion (cross bite) (Figure-5a) and opposing artificial teeth

All the steps of abutments preparation for both inlays and full crown retainer were followed as per the recommended textbooks (except when existing caries on the abutment in which all the caries was removed followed by modification of the cavity boxes for inlay preparations) [5\&8]. Standard diamond burs were used for the preparation of all abutments (KometBrasseler, Germany). Immediate application and polymerization of the dentine bonding agent to all freshly prepared dentin were done before impression making as recommended by MAGNE P, 2013[11].

\section{Impression, temporization and shade selection}

The final impressions for the prepared arch was made using addition silicon impression material (Virtual IvoclarVivadent, Schaan, Lichtenstein) using a two-step putty - reline impression technique, while the respective opposing arches were made usingdust free alginate impression materials. The provisional bridges were constructed from (Success SD, PROMEDICA NEUMUNSTER, Germany) and cemented with temporary cement (Temp-BondNT, Italy) (Figure-3a). Shade selections using the digital shade guide VITA System 3DMaster (Vita Easy-shade(R) Compact, Vita, Germany) were done.

\section{Prosthesis fabrications:}

The final impressions were poured with improved die stone type IV (Figure-2a). The wax-up (Figure$2 b$ ), investing and casting were done using respective manufacturer's instructions. The nickel chromium casting alloy used in this study was (Wiron 99, Bego, Germany) while the field-spathic porcelain used for build-up was with (VMK 95, Vita, Germany).

\section{Try-in and cementation:}

Metal - trial procedure was carried as done for routine fixed partial dentures except those castings which did not merge with the remaining occlusal contours of prepared teeth (Figure-3b, c,d). After sandblasting of the individual castings, porcelain build - up were completed(Figur-2c). During the final step, the areas of cementation were isolated with a cotton role. The inlays cavities were treated with $37 \%$ phosphoric acid (Total Etch) followed by a Primer application(Syntac). Later adhesive was applied (15sec and 10sec, respectively), while no such treatment was done for the prepared full crown retainers. The cement was applied to the inner surface of the inlays.Cementations of the glazed restorations were done with resin cement (Relaxy XTM, UnicemAppliCap Resin Cement, 3M ESPE, Germany (Figure- 4\&5). Occlusal biocompatibility of the restoration was done prior to final cementation using articulating paper to mark the necessary high points. The inlays prosthesis were finished with diamond burs and polished with a polishing system, while the proximal margins of inlays retainers were finished with Sof-Lex XT discs (3M ESPE, Germany). A glycerin gel was applied to the all border of the fitting surfaces in order to prevent oxygen inhibition. The post-operative $\mathrm{x}$ - rays were taken after cementation (Figuer-6). All the clinical steps as well as laboratory steps were carried by one operator. The maxillary and mandibular die casts for each case were done using Di-Lok tray (DiEqui Dental Products, Wappingers Falls N.Y) (Figure-2c).

\section{Follow-up Parameter:}

The clinical evaluations for the study were done after a period of 3 months from the final cementation. Where recall after 9, 18 and 36 months were done via telephone. The criteria of evaluation were suggested by Walton [12]. 
1. Successful: no need for any kind of intervention

2. In function: the patient could not examine directly, but confirmed no need for re-treatment.

3. Unknown: contact with the patient could not be established.

4. Repaired: the restoration was in function, but there was a need for major correction.

5. Failed: restoration lost retention with fracture of the framework or abutments.

All the data collected were analyzed according to the modified USPHA classification [13]. The evaluated criteria include post-operative sensitivity, gingival response to the hybrid fixed-fixed restoration, de-bonding of the retainers, secondary caries, retainer fracture resistance and patient satisfaction. The scoring system was; Excellent (a), Acceptable (b), Reparable (c) and Irreparable (d). All the baseline and follow-up clinical evaluations were done by a single examiner. In addition Kaplan-Meier survival estimating curve was performed [14].The data's were entered into the computer (MS-Office, Excel). The collected data were subjected to statistical analysis using the SPSS ver.12.0 (SPSS, Chicago, IL, USA).

\section{Results}

The clinical evaluation results on each of the follow up were found very good or excellent. According to Walton's criteria of clinical evaluation all patients fulfilled the criteria for successful at $3^{\text {rd }}$ and $9^{\text {th }}$ month, while a case was in-function at 18 months and four cases were repaired (re-cemented) at 36 months follow up (Table-1).

\begin{tabular}{|l|l|l|l|l|}
\hline & 3 months n-16 & 9 months n-16 & 18 months n-16 & 36 months n-16 \\
\hline Successful & 16 & 16 & 16 & 16 \\
\hline In-function & 0 & 0 & $15(94 \%)$ & $14(87.5 \%)$ \\
\hline Unknown & $\mathrm{O}$ & 0 & 0 & 0 \\
\hline Repaired & 0 & 0 & 0 & $14(87.5 \%)$ \\
\hline Failed & 0 & 0 & 0 & 0 \\
\hline
\end{tabular}

Table - 1: Survival rate according to Walton (12)

The result according to the Modified USPHS criteria shows that, the majority had absolutely no problem with the mentioned clinical evaluation parameters except for five cases. One case with free gingival inflammation around full retainers was attended as emergency at $18^{\text {th }}$ month. Two cases had slight post-operative sensitivity in maxillary arch which subsided later as confirmed on the last recall follow up. Also two cases showed debonding of the hybrid fixed-fixed bridges from the maxillary arches in 28 and 35 year old patients (Fig 7) at the 36 month follow-up. Overall the patient satisfactions of this type of restoration were $100 \%$ (Table -2 ).

\begin{tabular}{|l|l|l|l|l|l|}
\hline & Basic examination & 3 months & 9 months & 18 months & 36 months \\
\hline $\begin{array}{l}\text { Post-operative } \\
\text { sensitivity }\end{array}$ & 16 & $16 \mathrm{a}$ & $16 \mathrm{a}$ & $16 \mathrm{a}$ & $\begin{array}{l}14 \mathrm{a} \\
2 \mathrm{c}\end{array}$ \\
\hline Gingival response & 16 & $16 \mathrm{a}$ & $16 \mathrm{a}$ & $\begin{array}{l}15 \mathrm{a} \\
1 \mathrm{c}\end{array}$ & $16 \mathrm{a}$ \\
\hline $\begin{array}{l}\text { De-bonding of the } \\
\text { retainers }\end{array}$ & 16 & $16 \mathrm{a}$ & $16 \mathrm{a}$ & $16 \mathrm{a}$ & $\begin{array}{l}14 \mathrm{a} \\
2 \mathrm{c}\end{array}$ \\
\hline Secondary caries & 16 & $16 \mathrm{a}$ & $16 \mathrm{a}$ & $16 \mathrm{a}$ & $16 \mathrm{a}$ \\
\hline Fracture resistance & 16 & $16 \mathrm{a}$ & $16 \mathrm{a}$ & $16 \mathrm{a}$ & $16 \mathrm{a}$ \\
\hline Patient satisfaction & $100 \%$ & $100 \%$ & $100 \%$ & $100 \%$ & $100 \%$ \\
\hline
\end{tabular}

Table-2: Results according to the modified USPHS criteria (13)

The Kaplan-Meier probability is shown in (Fig 8). The success rate at 3 and 9 months were $100 \%$, while it decreases to $93.25 \%$ and $75 \%$ during 18 and 36 months respectively.

\section{Discussion}

Hybrid fixed-fixed retained FPDs are good alternative to conventional bilateral full coverage retained FPD, as they are less expensive, greater preservation of tooth structure and easier for periodontal assessment. ${ }^{[15]}$ Information on the longevity of hybrid FPDs should be considered in the selection of materials, operative techniques and patient instructions related to prognosis and long-term cost-effectiveness. ${ }^{[16]}$ Patient with occlusal factors such as absence of bruxism, good occlusal stability and the presence of remaining teeth are good candidates for such type of FPDs [3]. Immediate dentine sealing, appears to achieve improved bond strength, fewer gap formations, decrease bacterial leakage and reduced dentine sensitivity [11].

Absence of post-operative sensitivity of cases during 3,9,18 months could be because of the following causes, the use of glycerin gel which inhibits the oxidation of cement, polishing of the margins and the instructions recommended by the manufactures were followed during and after the final cementation [17]. While it appears at 36 months, this could be explained by starting of bond disintegration at this area [5].

One case with sign of periodontal inflammation was recorded around one crown in the maxillary arch. This could be explained by the fact that the location of the finish line at the distal aspect of the abutment was not being cleaned properly by the patient.

Two cases that de-bonded from the maxillary teeth can be explained by the action of the gravity and the presence of excessive amount of saliva from the parotid duct resulting in the dissolution of the cement [5]. 
Other factors include difference in the co-efficient of thermal expansion of the restorative materials as well as cements and tooth structures [5 \& 18]. These findings are in agreement with the finding of Ghavamnasiri et al,2010 [19] who concluded that de-bonding of this type of restorations is the main reason of failure. The finding of this study do agree with that of Song et al [20] who concluded that de-bonding in the premolar areas appeared to be due to smaller bonding area and the narrow connector dimension. In contrast to these findings our de-bonded cases were in molar area as shown in Fig 7. These results disagree with Ohlmann et al [17], who demonstrated de-bonding cases during first year may be due to the different in cementation materials and techniques used.

Occlusal adjustments were carried out before cementation. However, we re-checked occlusal contacts after cementation. Vallitu\&Sevelius, 2000 [21] concluded that de-bonding may be related to improper occlusal adjustments.

Secondary caries was not detected during the 36 months (evaluating periods), this is in agreement with Cenci et al, 2010 and Jevremovic et al, 2010 [16 \& 22]. Their cases were followed-up for 2 and 8 years respectively.

Our finding coincide with the finding of SARIDAG \& ÖZYESIL, 2008 and Sadeghi, 2008 [23 \&24], who concluded hybrid FPDs shows resistance to fractures more than to other types, due to materials used for fabrication of these types of bridges. This study showed a high success rate atshort term follow-up, which is in agreement with findings of Cenci et al, 2010 [11] \&Watzke et al, 2010 [25]

All the patients involved in this study were fully satisfied with the hybrid FPDs, even those show slight sensitivity or de-bonding. They were interesting in retreatment rather than the conventional full crown retained FPD. This is in agreement with Watzke et al, 2010 [25], they concluded patient satisfaction of the performance of this type of restoration after 18 months of cementation [25].

Overall our results agree with Hussey etal, 1991 [26], they conducted a study between 1984-1989 and concluded hybrid bridges design of FPD performance were well in the replacement of missing posterior teeth. HEMMINGS \& HARRINGTON, 2004 [27], recommended the usage of hybrid bridges due to recommendation possibility in case of de-bonding.

Since no modifications were occurred in the occlusal surfaces of the distal abutments during preparation phase. So the cemented cases were mounted manually during laboratory work. In other words the posterior vertical stops remain the same without modifications. The prosthesis replacement of the missed posterior teeth should be in harmony with the existing occlusion and coincide with the maximum inter-cuspation $[5]$.

\section{Conclusion}

Within the limits of this clinical study, the following conclusions were drawn:

1. Hybrid fixed-fixed bridges are conservative and appear to be an effective permanent restoration for posterior missing tooth.

2. Patients are generally satisfied with the treatment, even those exhibiting de-bonding or sensitivity and showed interest in re-treatment rather than full crown FPDs.

3. Practitioners should consider these types as an alternative to the conventional restorative options with some consideration such as patient selection, framework design and cement type.

4. Long-term clinical evaluations still needed to be carried out to evaluate the longevity and the oral performance of these types of restorations.

\section{References}

[1]. Piovesan EM, Demarco FF, Piva E: Fiber-reinforced fixed partial denture: a preliminary retrospective clinical study. J Appl Oral Sci 2006; 14: 100-4.

[2]. Jokstad A, Gokce M, Hjortsjo C: A systemic review of the scientific documentation of fixed partial dentures made from fiberreinforced polymer to replace missing teeth. Int J Prosthodont 2005; 18: 489-96.

[3]. Rappelli G, Coccia E: Fiber-reinforced composite fixed partial denture to restore missing posterior teeth: a case report. J Contemp Dent Prac 2005; 6: 168-177.

[4]. Tan K, Pjetursson BE, Lang NP \& Chan ES: A Systematic Review of the Survival and Complication Rates of Fixed Partial dentures (FPDs) after an Observation Period of at Least 5 Years. Clin Oral Implants Res 2004; 15(6):654-66.

[5]. Rosenstiel S, Land M and Fujimoto J: Contemporary Fixed Prosthodontics, $4^{\text {th }}$ edn. St Louis: Mosby Elsevier 2006. pp. pp 940, 175-200, 337-373.

[6]. Smith B GN: Planning and Making Crowns and Bridges, $3^{\text {ed }}$ edn, Mosby Co. 2006, pp 179.

[7]. Creugers N H, Käyser A F, Van't Hof M A: A seven-and-a-half-year survival study of resin-bonded bridges. J Dent Res 1992; 71 : $1822-5$.

[8]. Shillingburg H, Hobb S, Whitsett L, Jacobi R, Brackett S: Fundamentals of Fixed Prosthodontics. $4^{\text {th }}$ ed. Carol Stream. Quintessence Publishing Co 1997;pp.540

[9]. Carlo M, Paolo C, Özcan M: Inlay-Retained Zirconia Fixed Dental Prostheses: Modified Designs for a Completely Adhesive Approach. J Can Dent Assoc 2011; 77: 86-91.

[10]. Salameh Z, Sorrentino R, Ounsi HF, Goracci C, Tashkandi E, Tay F, et al: Effect of different all-ceramic crown system on fracture resistance and failure pattern of endodontically treated maxillary premolars restored with and without glass fiber posts. J 
Endod2007; 33:848-51.

[11]. MAGNE PASCAL: Immediate Dentine Sealing: A Fundamental Procedure for Indirect Bonded Restoration. Dent R \&Applis 2013; 1:2 0-26.

[12]. Walton JN, Gardner F M \& Agar JR: A Survey of Crown and Fixed Partial Denture Failures: Length of Service and Reasons for Replacement. J Prosth Dent 1986; 56:416-421.

[13]. Ryge G \& Snyder M: Evaluating the Clinical Quality or Restorations. J Am Dent Ass 1973; 87: 369-377.

[14]. HanniganAilish\&Lynach D Christopher: Statistical methodology in oral and dental research: Pitfalls and recommendations. J Dent 2013; 41:385-92.

[15]. LynchGaroushi S, Yokoyama D, Shinya A \& K. Vallittu P: Fiber-reinforced Composite Resin Prosthesis to Restore Missing Posterior Teeth. Ljm, AOP: 070414; 139-141.

[16]. Cenci M S, Rodolpho PA, Pereira-Cenci T, Del BelCury AA \& Demarco FF: Fixed Partial Dentures in an up to 8-Year FollowUp. J Appl Oral Sci 2010; 18: 364-71.

[17]. Ohlmann B, Rammelsberg P, Schmitter M, Schwarz S \&Gabbert O: All-Ceramic Inlay-Retained Fixed Partial Dentures: Preliminary Results From a Clinical Study. J Dent 2008; 36: 692-96.

[18]. Craig RG: Restorative Dental Materials, 13th Ed. The Mosby Co 2012; p 212, 344.

[19]. Ghavamnasiri M, Malknejad F \&Modabber M: Porcelain fused to metal crown as an abutment of a metal-ceramic resin-bonded fixed partial denture: a clinical report. J Contemp Dent Pract 2010; 11: 64-70.

[20]. Song HY, Yi YJ, Cho LR \& Park DY: Effects of Two Preparation Designs and Pontic Distance on Bending and Fracture Strength of Fiber-Reinforced Composite Inlay Fixed Partial Dentures. J Prosth Dent 2003; 90; 347-53.

[21]. Vallitu PK \&Sevelius C: Resin-Bonded Glass Fiber- Reinforced Composite Fixed Partial Dentures; A Clinical Study. J Prosth Dent 2000; 84: 413-18.

[22]. Jevremovic DP, Boškovic MV, Puškar T, Williams R, Trifkovic B \&Eggbeer D: A Clinical Evaluation of Inlay-Retained Fixed Partial Dentures After a Two - Year Observation Period. ActaStomatologiNassi 2010; (26) 62: 997-1006.

[23]. Serkan SARIDAG S \& ÖZYESIL AG: Conservative Alternative for the Replacement of Missing Posterior Teeth: Two Case Reports. SÜ DishekFak Der 2008; 17: 216-220.

[24]. Sadeghi M: Fracture Strength and Bending of Fiber-Reinforced Composite and Metal Framework in Fixed Partial Denture. J Dent, Tahran University of Medical Sienc 2008; 5: 99-104.

[25]. Watzke R, Peschke A \&Roulet JF: Clinical Behavior of All-Ceramic Inlay-Retained Bridges after 18 Months. (2010); IADR General Session Poster (July 14-17).

[26]. Hussey DL, Pagni C \& Linden GJ: Performance of 400 adhesive bridges fitted in a restorative dentistry department. J Dent 1991; 19: 221-5.

[27]. HEMMINGS K \& HARRINGTON Z: Replacement of Missing Teeth with Fixed Prostheses. Dental Update (2004); April: 137- 4.

\section{Legend}

Figure-1: Preoperative and radiographic views

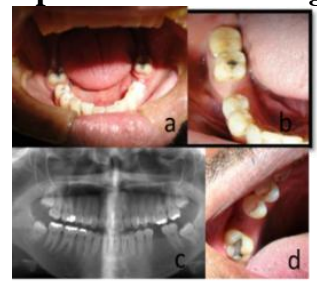

Figure-2: Cases during laboratory steps

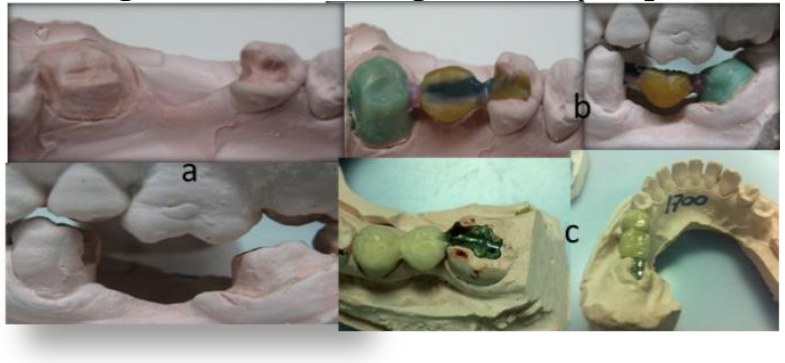

Figure-3: Cases during clinical steps

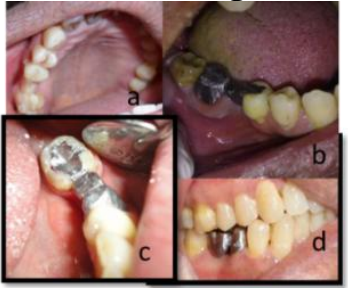

Figure-4: Occlusal view of cemented cases 


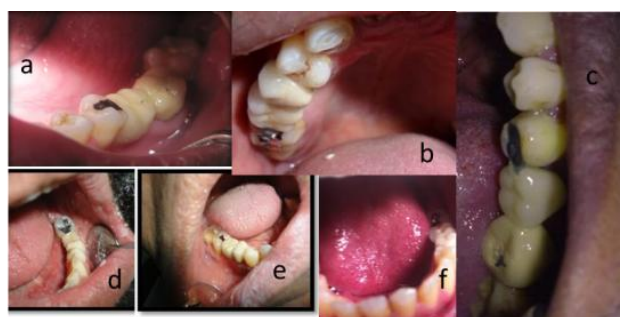

Figure-5: Cemented cases during maximum inter-cusption

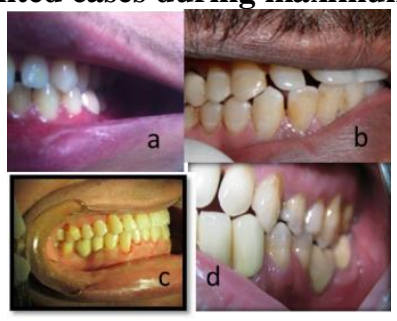

Figure-6: Post-operative Radiographic views of some cases

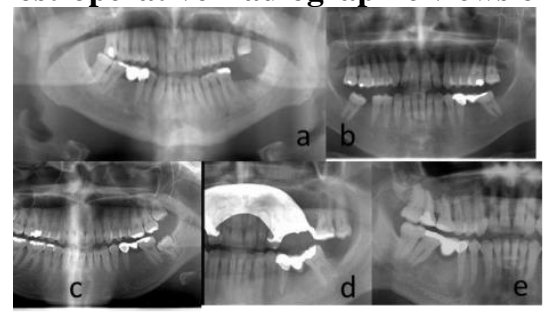

Figure-7: Post-operative de-bond case

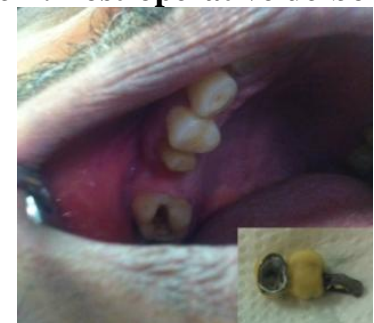

Figure-8: Kaplan-Meier survival probability during the 36 months examination period

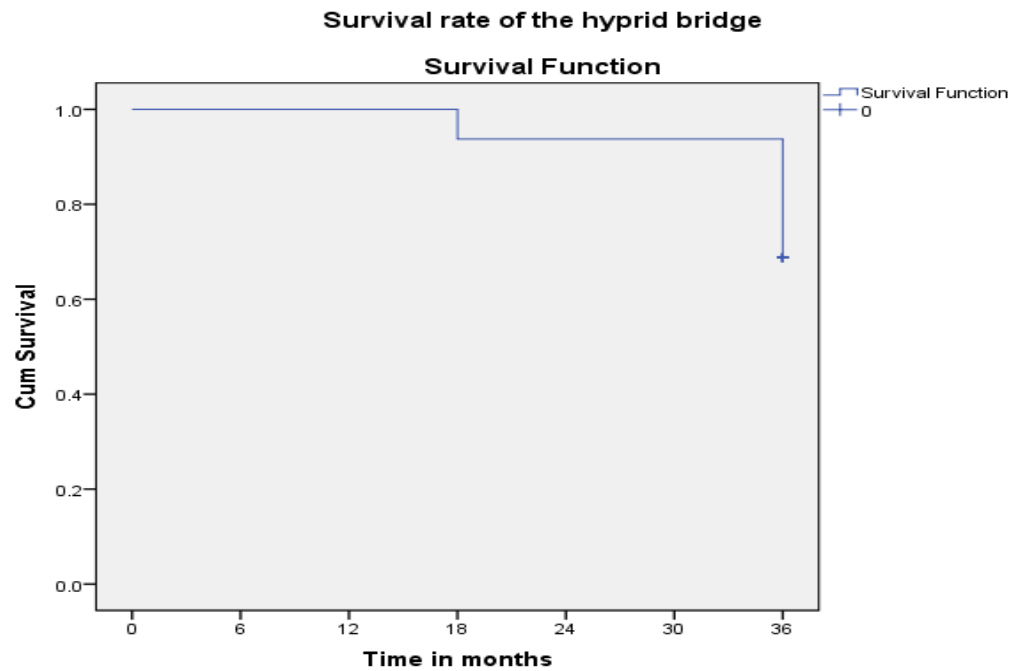

